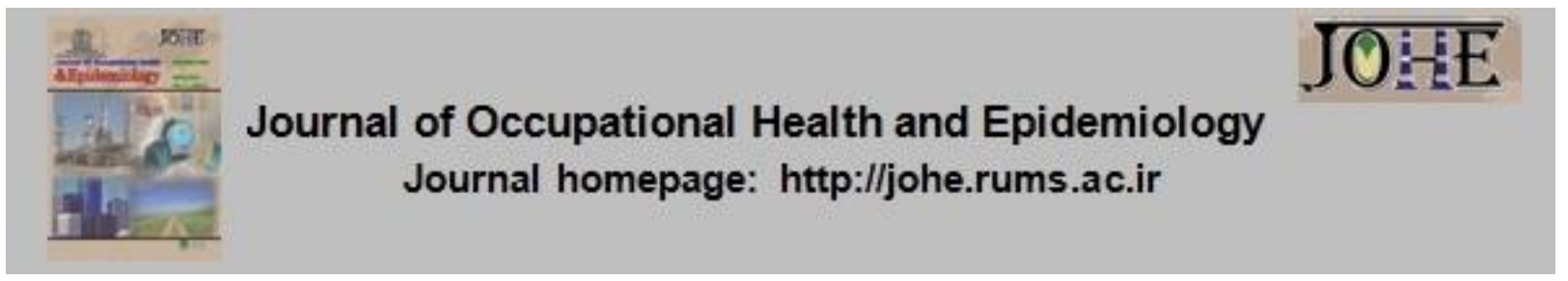

\title{
Hematological and hepatic alterations among copper mine workers and office employees in a copper mine in the west of Iran, 2015
}

\author{
Haghighat Lotfi ${ }^{1}$, Hassan Rezazadeh ${ }^{2}$, karim Ebrahim ${ }^{3,{ }^{*}}$ \\ 1- MSc in Toxicology, Department of Toxicology, School of Pharmacy, Islamic Azad University of Ahar, Ahar, Iran. \\ 2- Associate Prof., Department of Pharmacology and Toxicology, Faculty of Pharmacy,Tabriz University of Medical \\ Sciences, Tabriz, Iran. \\ 3- Assistant Prof., Department of Environmental Health Engineering, School of Health, Isfahan University of Medical \\ Sciences, Isfahan, Iran.
}

\section{Article Info}

* Corresponding authors: karim Ebrahim,

E-mail:

k.najafabady@sbmu.ac.ir

Article history

Received: Nov, 2017

Accepted: Jan, 2018

Print ISSN: $2251-8096$

Online ISSN: 2252-0902

Peer review under responsibility of Journal of Occupational Health and Epidemiology

\begin{abstract}
Background: Workers in different occupational positions experience significant $\mathrm{Cu}$ exposures, however, $\mathrm{Cu}$ toxicity has not been fully studied as compared to other heavy metals. In the present study, hematological and hepatic alterations have been investigated among copper mine workers.

Materials and Methods: This descriptive study was conducted in a copper mine in west of Iran, on 402 copper mine workers (study group) and 52 office employees (control group) during winter 2015. $5 \mathrm{ml}$ blood samples were provided from each subject and hematological and hepatic parameters including white blood cell (WBC), platelet (PLT), hemoglobin (HGB), hematocrit (HCT), mean corpuscular volume (MCV), mean corpuscular hemoglobin concentration $(\mathrm{MCH})$, lymphocytes, neutrophils, alanine aminotransferase (ALT), aspartate aminotransferase (AST) and serum $\mathrm{Cu}$ levels have been determined using their commercial kits. The results were analyzed in the SPSS software using t-test and regression method.

Results: ALT, AST, HGB, MCV, MCH and plasma Cu levels among the workers were significantly higher than the office employees $(p<0.050)$. WBC and RBC counts among the workers were significantly lower than the control group ( $p=0.049$ and 0.024 , respectively). Serum Cu levels of 215 of the workers were higher than its normal recommended range $(120 \mu \mathrm{g} / \mathrm{dl})$. For the subjects with serum Cu levels above $150 \mu \mathrm{g} / \mathrm{dl}$, increases in AST and ALT were in compliance with serum Cu levels increase.

Conclusions: Significant hepatic and hematological alteration were observed among copper miners compared to control group. Employment of workers with background hematological and hepatic disorders in copper industries must be accompanied with great caution.
\end{abstract}

Keywords: Copper, Toxicity, Liver, Hematologic Diseases, Miners

\section{Introduction}

Copper $(\mathrm{Cu})$ is an essential trace element found in all living organisms. Numerous physiological functions have been reported for $\mathrm{Cu}$. $\mathrm{Cu}$ is necessary for structural and catalytic activity of a variety of important enzymes, including cytochrome $C$ oxidase, tyrosinase, dopamine beta hydroxylase $(\mathrm{DBH})$ and $\mathrm{Cu}$-zinc super oxidase dismutase (Cu, Zn SOD). Cu supplements were used to treat anemia among animals

(C) The Author(s) 2018. Published by Rafsanjan University of Medical Sciences Press.

All rights reserved. For permissions, please e-mail: johe.rums@gmail.com, johe@rums.ac.ir 
since 1920s and $\mathrm{Cu}$ deficiency was documented among humans in the 1960s, respectively (1).

Sources of environmental exposure to $\mathrm{Cu}$ include water pipes, cookware, contraceptive pills, vitamin and minerals supplements and fungicides with $\mathrm{Cu}$ is added for swimming pools. Plumbers, welders and machinists occupationally expose to $\mathrm{Cu}$ and are at risk of $\mathrm{Cu}$ toxicity (2). High levels of $\mathrm{Cu}$ exposure were reported among individuals working in copper-smelting areas and copper mines (3, 4).

$\mathrm{Cu}$ acute poisoning is a rare condition and most reports on $\mathrm{Cu}$ toxicity among human were related to its chronic and sub-chronic exposures. $\mathrm{Cu}$ chronic toxicity has been reported among patients undergoing dialysis treatment who receive dialysis fluid via $\mathrm{Cu}$ tubing and workers in pesticides industry (5).

After gastrointestinal or respiratory absorption, Cu mainly deposits in liver and its chronic toxicity primarily affects the liver. $\mathrm{Cu}$ toxicity is typically manifested by the development of liver cirrhosis with episodes of hemolysis and damage to renal tubules, brain and other organs. Symptoms can progress to coma, hepatic necrosis, vascular collapse and death. $\mathrm{Cu}$ poisoning may result in weakness, lethargy and anorexia in the early stages in addition to erosion of the epithelial lining of the gastrointestinal tract, hepatocellular necrosis and acute tubular necrosis (6). Background disease like anemia and hepatic disorders could exacerbate toxic effects of $\mathrm{Cu}$ excess. Women and elderlies are more sensitive to copper toxicity (7).

Experimental studies demonstrated that $\mathrm{Cu}$ excess induces dose and time dependent changes in hepatic enzymes activities and fatty liver syndrome among fish (8, 9). Among rats, chronic $\mathrm{Cu}$ exposure at subtoxic level results in liver and kidney dysfunctions. $\mathrm{Cu}$ induced oxidative stress among fish liver suggests the involvement of differential mechanisms in Cu uptake and toxicity $(9,10)$. Two studies on sheep showed that sub-acute $\mathrm{Cu}$ exposure induce jaundice, anorexia, excessive thirst, hemoglobinuria and dramatic reductions in blood hemoglobin and glutathione concentrations. Transient increases have been reported in blood methemoglobin (11, 12).

Despite of these evidences about copper toxicity, there are a few studies on $\mathrm{Cu}$ hepatic and hematological effects among humans in the literature (7). Therefore, the present descriptive study was conducted with the aim to assess hematological and hepatic alterations among workers of a copper mine (in west of Iran) and office employees of this mine in winter 2015.

\section{Material and Methods}

This descriptive study was conducted in a copper mine in west of Iran, during winter 2015. 402 copper mine worker and 52 office employees were participated in this study as study and control groups, respectively. These exposed and un-exposed groups had the same conditions in terms of age, gender, race, working location and living areas.

All workers of the mine were participated in the study and were divided in two groups including, copper mine workers from different areas of the mine (as exposed group, $n=402$ ) and office employees of this mine working in an office building, $5 \mathrm{~km}$ far away from the mine (as un-exposed group, $\mathrm{n}=52$ ). All subjects were men and two study groups were in the same conditions in terms of age, smoking status and living area. Necessary information like demographic characteristics (age, race, gender and occupational roles), smoking, medical and occupational history, special diet, residence location and secondary jobs were collected through a questionnaire before sampling, then the questionnaires were reviewed by the investigators for 
identifying confounding factors. To avoid confounding factors, subjects were included only if they were with the lack of a history of smoking, hepatic or hematological diseases and background exposures to $\mathrm{Cu}$. The proposal of the study has been approved by Islamic Azad University-Ahar Branch ethics committee. All of the subjects were provided with an informed consent.

Blood samples (venous blood, $5 \mathrm{ml}$ ) were collected aseptically using sterile $5 \mathrm{ml}$ syringe. Serum was separated by centrifugation (Hettich Zentrifugen, Tuttlingen, Germany) of blood at $3000 \times g$ for 10 minutes at room temperature, then the sera were transferred into $1.5 \mathrm{ml}$ sterile microtubes and hematological and hepatic markers were determined. The selected markers included: red blood cell (RBC) counts, white blood cell (WBC) counts, platelet (PLT) counts, hemoglobin (HGB), hematocrit (HCT), mean corpuscular volume (MCV), mean corpuscular hemoglobin concentration $(\mathrm{MCH})$, lymphocyte counts (LYM), neutrophil percent (NEUT), serum concentration of aspartate aminotransferase (AST) and alanine aminotransferase (ALT). All samples were analyzed in a qualified central laboratory by a biochemical automatic analyzer (Autolab, AMS Corporation, Rome, Italy) using their commercial kits (Pars Azmoon, Esfahan, Iran). Serum copper was analyzed by its commercial kit (Zist-shimi, Tehran, Iran) according to manufacturer's instructions. All laboratory tests were performed in an approved medical lab in Tabriz, Iran, during winter 2015.

All measurements were repeated in triplicate and the data were presented as mean \pm standard deviation (SD). Prior to statistical analysis, Shapiro-Wilk test was applied to determine the normal distribution of data. For assessment of the correlation between serum $\mathrm{Cu}$ levels and hematological/hepatic changes, Pearson and Spearman's correlation coefficient analysis was performed for data with normal and non-normal distribution, respectively. Student t-test was used for detection of differences in hematological and hepatic markers among exposed and unexposed groups. Statistical analysis was performed using the SPSS (version 20, IBM Corporation, Armonk, NY, USA) statistical software package. A probability of $\mathrm{P}<0.050$ was considered statistically significant.

\section{Results}

Demographic characteristics of study and control groups are summarized in table 1 . No statistically significant difference was observed between the ages of exposed and the control group with mean \pm SD of $36.00 \pm$ 5.87 and $34.00 \pm 6.65$, respectively $(P=$ $0.017)$. Mean \pm SD of each hematological and hepatic parameter for copper mine workers and office employees of this mine are presented in table 1. Shapiro-Wilk test confirmed normal distribution of data for all parameters $(P=0.037)$.

ALT and AST levels among the miners were significantly higher than office employees ( $P$ $<0.500)$. WBC and RBC count decreased significantly among the miners $(P=0.049$, 0.024 ) compared to control group. $\mathrm{MCH}$ increased significantly $(P<0.0001)$. HCT, PLT, LYM and NEUT levels showed no significant differences between study and control groups $(P>0.050)$. Significant decrease of hemoglobin levels was observed among the mine workers compared to office employees $(P=0.003)$. Linear regression showed no significant relation between increase in serum $\mathrm{Cu}$ levels and increase of AST and ALT ( $P$ > 0.050).

Serum $\mathrm{Cu}$ levels of workers in some areas of mine reached the rate of $230 \mu \mathrm{g} / \mathrm{dl}$ and its mean concentrations were significantly higher than recommended reference range (90-120 $\mu \mathrm{g} / \mathrm{dl})$. 
Table 1: Hematological and hepatic parameters for workers and office employees of a copper mine in west Iran, winter 2015

\begin{tabular}{|c|c|c|c|c|c|c|}
\hline \multirow{2}{*}{ Parameter } & \multicolumn{2}{|c|}{$\begin{array}{c}\text { Copper mine } \\
\text { workers }(n=402)\end{array}$} & \multicolumn{2}{|c|}{$\begin{array}{l}\text { Office employees } \\
(n=52)\end{array}$} & \multirow{2}{*}{$\begin{array}{l}\text { Reference } \\
\text { interval }\end{array}$} & \multirow[t]{2}{*}{$\begin{array}{c}\mathrm{P} \text { of } \\
\text { T-test }(95 \%)\end{array}$} \\
\hline & Mean & SD & Mean & SD & & \\
\hline$\overline{A S T}(\mathrm{IU} / \mathrm{I})$ & 22.59 & 9.17 & 20.56 & 6.46 & Up to 41 & 0.045 \\
\hline $\mathrm{ALT}(\mathrm{IU} / \mathrm{I})$ & 31.60 & 13.23 & 27.20 & 12.18 & Up to 47 & 0.036 \\
\hline WBC count $\left(\times 10^{3} / \mu \mathrm{l}\right)$ & 7.00 & 1.86 & 7.40 & 7.71 & $4-11.3$ & 0.049 \\
\hline RBC count $\left(\times 10^{6} / \mu \mathrm{l}\right)$ & 5.34 & 0.40 & 5.47 & 0.41 & $4.5-5.9$ & 0.024 \\
\hline $\mathrm{HGB}(\mathrm{g} / \mathrm{dl})$ & 15.27 & 1.18 & 15.82 & 1.26 & $13.5-17.5$ & 0.003 \\
\hline HCT (\%) & 46.29 & 3.04 & 46.14 & 3.16 & $42-50$ & 0.756 \\
\hline $\operatorname{MCV}(\mathrm{fl})$ & 86.72 & 3.01 & 84.32 & 6.63 & $80-96.1$ & 0.011 \\
\hline $\mathrm{MCH}(\mathrm{pg})$ & 29.64 & 1.26 & 27.96 & 2.67 & $27-33.2$ & $<0.001$ \\
\hline PLT $\left(\times 10^{3} / \mu \mathrm{l}\right)$ & 227.76 & 51.24 & 222.76 & 48.05 & $140-250$ & 0.472 \\
\hline LYM (\%) & 39.77 & 9.38 & 40.15 & 7.65 & $25-45$ & 0.724 \\
\hline NEUT (\%) & 48.32 & 9.45 & 47.49 & 8.20 & $35-75$ & 0.533 \\
\hline $\mathrm{Cu}(\mu \mathrm{g} / \mathrm{dl})$ & 123.21 & 27.24 & 94.96 & 15.06 & $70-120$ & $<0.0001$ \\
\hline
\end{tabular}

* AST: Aspartate aminotransferase; ALT: Alanine transaminase; WBC: White blood cells; RBC: Red blood cells; HGB: Hemoglobin; HCT: Hematocrit; MCV: Mean cell volume; PLT: Platelet; LYM: Lymphocytes; NEUT: Neutrophils; Cu: Copper

\section{Discussion}

$\mathrm{Cu}$ in its ionic form rapidly becomes toxic to a variety of cells including hepatic and hemal systems. Excessive intracellular accumulation of $\mathrm{Cu}$ promotes formation of reactive oxygen species (ROS), catalyzing the reaction between the superoxide anion and hydrogen peroxide and production of hydroxyl radical. Furthermore, $\mathrm{Cu}$ can bind directly to free thiols of cysteines (Cys), leading to oxidation and crosslinks between proteins, thus inactivating enzymes or impairing structural proteins (13). Cu induced ROS generation initiate apoptotic/necrotic processes or other pathologies like cancer, neurological diseases, and aging (14). It was found that, multiple sclerosis (MS) subjects had increased levels of $\mathrm{Cu}$ in their fluids or brain cells (15).

The results of the present study showed that serum AST and ALT levels among workers were significantly higher than the office employees. In the case of AST, this increase was not very serious and only 12 miners showed elevated levels (above 41 $\mathrm{IU} / \mathrm{I}$ ) of AST while serum ALT levels of 48 miners were in alarming way, above its reference level (47 IU/I). As alcoholic beverages are forbidden in Iran, this increase cannot be due to the distractive effects of alcohol on hepatic cells. The AST/ALT ratios for these workers were below or equal to 1 indicating non-alcoholic hepatic injuries.

As mentioned above, in the initial analysis of the results, linear regression showed no significant relation between increase in serum $\mathrm{Cu}$ levels and increase of AST and $A L T$, however, the detailed analysis showed that among subjects with serum $\mathrm{Cu}$ levels above $150 \mu \mathrm{g} / \mathrm{dl}$, increase in AST and ALT is in compliance with serum $\mathrm{Cu}$ levels increase (Figure 1A and 1B). A study by Sakhaee et al. also showed significant increase in serum ALT and AST levels among the individuals living in residential areas near the copper smelting complex (16). Another study by Kumar et al. showed that $\mathrm{Cu}$ mainly concentrated in liver (29 folds higher than kidney) and Serum ALT, AST and bilirubin correlated with liver $\mathrm{Cu}$ among rats (11). As, increase in AST and ALT levels is an important indicator for hepatic injury, routine monitoring of serum AST and ALT levels among the copper miners is necessary. 

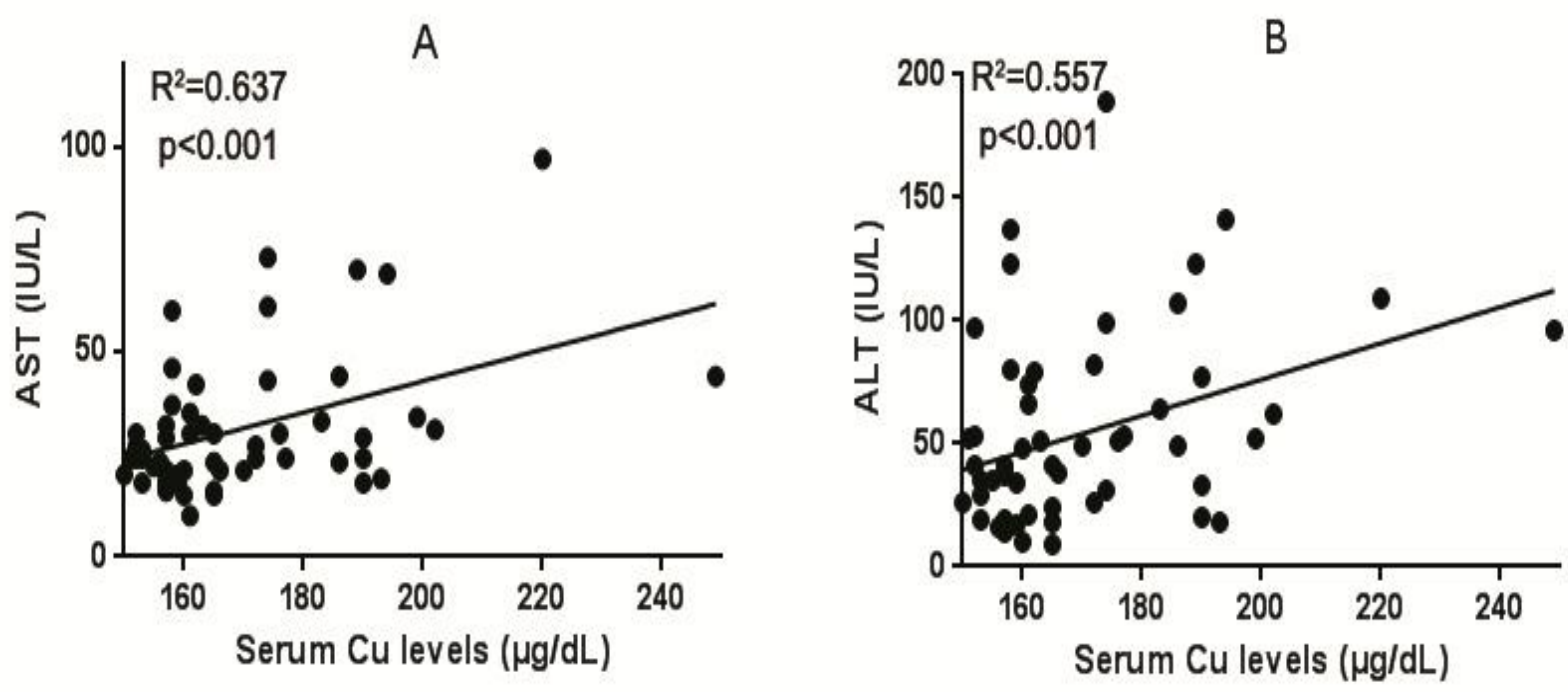

Figure 1: Correlation between serum $\mathrm{Cu}$ levels and hepatic injury indexes (ALT and AST) among workers of a copper mine in west of Iran, winter 2015

As seen in table1, RBC and WBC counts and hemoglobin content decrease significantly among the miners compared to the control group. Two previous studies on toxic effects of $\mathrm{Cu}$ on hematological system of the fish confirmed decrease of RBC count and hemoglobin content due to Cu toxicity, however, increase in WBC counts was reported in both studies $(17,18)$. This finding is in conflict with the results of the present study, which may be due to the different mechanisms of $\mathrm{Cu}$ toxicity among humans and fish. Further studies are required for better understanding of exact effects of $\mathrm{Cu}$ toxicity on WBC count. Furthermore, no direct correlations were found between increase in serum $\mathrm{Cu}$ levels and changes in hematological parameters, however, it is obvious that $\mathrm{Cu}$ toxicity could impose potent hematological consequences and continuous monitoring of these parameters among the exposed individuals is recommended.

$\mathrm{Cu}$ is sequestered in blood by the ceruloplasmin and its serum $\mathrm{Cu}$ level reflects recent exposures (19). In the literature, various levels were reported for serum copper concentrations among different human populations. Some of the recent studies in this filed are summarized in table 2. As expected, mean serum $\mathrm{Cu}$ levels of the office employees showed no significant difference with Iranian general population, however, its levels among the mine workers were significantly high. Serum $\mathrm{Cu}$ levels among 215 and 74 of workers were higher than its normal recommended range $(120 \mu \mathrm{g} / \mathrm{dl})(20)$ and above $150 \mu \mathrm{g} / \mathrm{dl}$, respectively. It seems that copper mine workers experience intensive $\mathrm{Cu}$ exposures which can cause considerable health effects for them.

It should be noted that the number of subjects in control group (office employees of copper mine, $n=52$ ) was lower than the study group $(n=402)$. It was a limitation for this study and could affect the study results. However, the office employees of this mine were the best match cases for control group of this study but unfortunately only 65 persons worked in this position. We suggest further studies on Cu-exposed workers with larger control groups. 
Table 2: Mean serum $\mathrm{Cu}$ levels among different populations

\begin{tabular}{ccc}
\hline Populations & $\begin{array}{c}\text { Mean serum Cu } \\
\text { levels }(\boldsymbol{\mu g} / \mathbf{d l})\end{array}$ & Reference \\
\hline Italian (general population) & 122.50 & $(21)$ \\
\hline Brazilian (general population) & 89.00 & $(22)$ \\
\hline Chinese (general population) & 108.10 & $(23)$ \\
\hline German (general population) & 102.00 & $(24)$ \\
\hline Swedish (general population) & 85.50 & $(25)$ \\
\hline Indian and Pakistani (general population) & 103.00 & $(26)$ \\
\hline Jordanian (Smokers) & 232.80 & $(16)$ \\
\hline Iranian (living near copper smelting & 94.80 & $(20)$ \\
\hline complexes) & 93.63 &
\end{tabular}

\section{Conclusion}

The findings of the present study showed significant hepatic and hematological alteration among copper mine workers compared to the control group. These effects were in correlation with serum $\mathrm{Cu}$ levels. Employment of workers with background hematological and hepatic disorders in copper industries must be accompanied with great caution. In periodic medical checkup of workers, the physician should have a greater focus on the hematological and hepatic symptoms.

\section{Acknowledgment}

This study is part ofa thesis submitted for M.Sc. degree of Mrs. Haghighat Lotfi in Department of Toxicology, School of Pharmacy, Ahar Branch, Islamic Azad University, Ahar, Iran. This study was performed by self-funding of the researchers. The authors appreciate Mrs. Forough Forouzandeh for all of her supports.

Conflict of interest: None declared.

\section{References}

1. Tapiero H, Townsend DM, Tew KD. Trace elements in human physiology and pathology. Copper. Biomed Pharmacother 2003; 57(9):386-98.
2. Gaetke LM, Chow-Johnson HS, Chow CK. Copper: toxicological relevance and mechanisms. Arch Toxicol 2014; 88(11):1929-38.

3. Nieboer E, Thomassen $\mathrm{Y}$, Romanova $\mathrm{N}$, Nikonov A, Odland JØ, Chaschin V. Multicomponent assessment of worker exposures in a copper refinery. Part 2. Biological exposure indices for copper, nickel and cobalt. J Environ Monit 2007; 9(7):695-700.

4. Thomassen $\mathrm{Y}$, Nieboer $\mathrm{E}$, Romanova N, Nikanov A, Hetland S, VanSpronsen EP, et al. Multi-component assessment of worker exposures in a copper refinery Part 1. Environmental monitoring. J Environ Monit 2004; 6(12):985-91.

5. Pohl HR, Roney N, Abadin HG. Metal ions affecting the neurological system. Met lons Life Sci 2010; 8:247-62.

6. Klaassen CD, Watkins III JB. Casarett \& Doull's essentials of toxicology. $3^{\text {rd }}$ ed. New York, United States: McGraw-Hill Education; 2015. P.952-4

7. Prasad AS. Essential and toxic element: trace elements in human health and disease. $1^{\text {st }}$ ed. Cambridge, Massachusetts, United States: Academic Press; 2013. P.302-3

8. Beshgetoor D, Hambidge M. Clinical conditions altering copper metabolism in humans. Am J Clin Nutr 1998; 67(5 Suppl):1017S-21S.

9. Kim SG, Kang JC. Effect of dietary copper exposure on accumulation, growth and hematological parameters of the juvenile rockfish, Sebastes schlegeli. Mar Environ Res 2004; 58(1):65-82.

10. Liu XJ, Luo Z, Xiong BX, Liu X, Zhao YH, Hu GF, et al. Effect of waterborne copper exposure on growth, hepatic enzymatic activities and histology in Synechogobius 
hasta. Ecotoxicol Environ Saf 2010; 73(6):1286-91.

11. Kumar V, Kalita J, Misra UK, Bora HK. A study of dose response and organ susceptibility of copper toxicity in a rat model. J Trace Elem Med Biol 2015; 29:26974.

12. Sanchez W, Palluel O, Meunier L, Coquery M, Porcher JM, Ait-Aissa S. Copper-induced oxidative stress in three-spined stickleback: relationship with hepatic metal levels. Environ Toxicol Pharmacol 2005; 19(1):17783.

13. Bremner I. Manifestations of copper excess. Am J Clin Nutr 1998; 67(5 Suppl):1069S73S.

14. Aydemir B, Kiziler AR, Onaran I, Alici B, Ozkara $\mathrm{H}$, Akyolcu MC. Impact of $\mathrm{Cu}$ and $\mathrm{Fe}$ concentrations on oxidative damage in male infertility. Biol Trace Elem Res 2006; 112(3):193-203.

15. Letelier ME, Sánchez-Jofré S, Peredo-Silva $\mathrm{L}$, Cortés-Troncoso J, Aracena-Parks P. Mechanisms underlying iron and copper ions toxicity in biological systems: Pro-oxidant activity and protein-binding effects. Chem Biol Interact 2010; 188(1):220-27.

16. Sakhaee E, Behzadi MJ, Shahrad E. Subclinical copper poisoning in asymptomatic people in residential area near copper smelting complex. Asian Pac J Trop Dis $2012 ; 2(6): 475-7$.

17. Singh D, Nath K, Trivedi SP, Sharma YK. Impact of copper on haematological profile of freshwater fish, Channa punctatus. J Environ Biol 2008; 29(2):253-7.

18. Van Vuren $\mathrm{JH}$, Van der Merwe M, du Preez $\mathrm{HH}$. The effect of copper on the blood chemistry of Clarias gariepinus (Clariidae). Ecotoxicol Environ Saf 1994; 29(2):187-99.

19. Bocca B, Madeddu R, Asara Y, Tolu P, Marchal JA, Forte G. Assessment of reference ranges for blood $\mathrm{Cu}, \mathrm{Mn}$, Se and $\mathrm{Zn}$ in a selected Italian population. J Trace Elem Med Biol 2011; 25(1):19-26.
20. Ghayour-Mobarhan M, ShapouriMoghaddam A, Azimi-Nezhad M, Esmaeili H, Parizadeh SM, Safarian $M$, et al. The relationship between established coronary risk factors and serum copper and zinc concentrations in a large Persian cohort. J Trace Elem Med Biol 2009; 23(3):167-75.

21. Minoia C, Sabbioni E, Apostoli P, Pietra R, Pozzoli L, Gallorini M, et al. Trace element reference values in tissues from inhabitants of the European community. I. A study of 46 elements in urine, blood and serum of Italian subjects. Sci Total Environ 1990; 95:89-105.

22. Nunes JA, Batista BL, Rodrigues JL, Caldas NM, Neto JA, Barbosa F Jr. A simple method based on ICP-MS for estimation of background levels of arsenic, cadmium, copper, manganese, nickel, lead, and selenium in blood of the Brazilian population. J Toxicol Environ Health A 2010; 73(1314):878-87.

23. Liu J, Yang $H$, Shi $H$, Shen $C$, Zhou W, Dai $Q$, et al. Blood copper, zinc, calcium, and magnesium levels during different duration of pregnancy in Chinese. Biol Trace Elem Res 2010; 135(1-3):31-7.

24. Heitland $P$, Köster HD. Biomonitoring of 37 trace elements in blood samples from inhabitants of northern Germany by ICP-MS. J Trace Elem Med Biol 2006; 20(4):253-62.

25. Rosborg I, Hyllén E, Lidbeck J, Nihlgård B, Gerhardsson L. Trace element pattern in patients with fibromyalgia. Sci Total Environ 2007; 385(1-3):20-7.

26. Abdulla M, Suck C. Blood levels of copper, iron, zinc, and lead in adults in India and Pakistan and the effect of oral zinc supplementation for six weeks. Biol Trace Elem Res 1998;61(3):323-31.

27. Massadeh A, Gharibeh A, Omari K, AlMomani I, Alomary $\mathrm{A}$, Tumah $\mathrm{H}$, et al. Simultaneous determination of $\mathrm{Cd}, \mathrm{Pd}, \mathrm{Cu}$ $\mathrm{Zn}$ and $\mathrm{Se}$ in human blood of jordanian smokers by ICP-OES. Biol Trace Elem Res 2010; 133(1):1-11. 